\title{
O JOGO COMO FORMA COMPLEXA DO DISCURSO: UMA ABORDAGEM ENUNCIATIVA DE UMA AULA DE FRANCÊS*
}

Silvana Silva**

(D) https://orcid.org/0000-0002-4069-580X

Larissa Freisleben ${ }^{\star * *}$

https://orcid.org/0000-0002-2191-1730

Como citar este artigo: SILVA, S.; FREISLEBEN, L. O jogo como forma complexa do discurso: uma abordagem enunciativa de uma aula de francês. Todas as Letras - Revista de Lingua e Literatura, São Paulo, v. 23, n. 2, p. 1-14, maio/ago. 2021. DOI 10.5935/1980-6914/eLETLL2113324.

Submissão: abril de 2020. Aceite: julho de 2020.

Resumo: O trabalho propõe uma análise enunciativa, a partir da perspectiva da Linguística da Enunciação de Émile Benveniste, de uma aula de francês como língua adicional na qual o jogo foi utilizado como um recurso didático. Na primeira parte, propomos que o jogo pode ser entendido como uma forma complexa do discurso. Na segunda parte, analisamos trechos transcritos dessa aula. Propomos que nesse contexto o jogo assume uma configuração específica, pois está submetido a uma situação de ensino-aprendizagem na qual os locutores assumem papéis discursivos diversos que se entrecruzam.

Palavras-chave: Enunciação. Formas complexas do discurso. Jogo. Ensino de lingua francesa. Émile Benveniste. 


\section{INTRODUÇÃo}

O objeto central deste trabalho é a análise enunciativa da aplicação de jogos com fins didáticos em aulas de lingua francesa. Para tanto, valemo-nos da teoria enunciativa de Émile Benveniste na busca de subsídios para a análise de situações concretas de aplicação de jogos em sala de aula.

Segundo Flores (2013), aquilo que denominamos teoria da enunciação de Émile Benveniste é uma consequência da leitura de seus artigos publicados, principalmente aqueles reunidos nas obras Problemas de Linguística Geral, volumes I e II. No entanto, sua reflexão ultrapassa o pensamento estritamente linguístico. Sua extensa obra dialoga com o pensamento da época, e é possivel encontrar textos sobre Antropologia, Psicanálise, Filosofia e outras áreas. O ponto de partida deste trabalho é um desses textos, chamado "Le jeu comme structure".

Originalmente publicado na revista Deucalion, Cahiers de Philosophie n. 2, em 1947, encontra-se também na coletânea Langues, cultures, religions, organizada por Chloé Laplantine e Georges-Jean Pinault, na qual estão reunidos artigos de Émile Benveniste que correspondem a uma parte de sua produção, como se lê no prefácio, "que ultrapassa a estrita especialização linguística, integrando-a, porque esses trabalhos se voltam para a significação, para a dimensão antropológica do discurso, para as posições sociais dos locutores" (LAPLANTINE; PINAULT, 2015, p. XIII, tradução nossa ${ }^{1}$ ).

A reflexão de Benveniste sobre a linguagem caracteriza-se pela presença de uma triade epistemológica: homem, linguagem e cultura (FLORES, 2013). Sua linguística abre espaço para reflexões sobre o homem na lingua, inaugurando uma antropologia da linguagem. Considerando que a enunciação não é um nível de análise linguística, uma vez que os locutores, ao enunciar, mobilizam a língua toda, a teoria da enunciação permite a análise de qualquer fenômeno linguístico, passando por todos os níveis da língua e priorizando o sentido. A partir da compreensão de que é possivel analisar qualquer fenômeno linguístico e da leitura do texto de Benveniste já mencionado, propusemo-nos a analisar uma manifestação específica do jogo: as atividades assim denominadas que são propostas em aulas de língua adicional.

Para além da reflexão de Benveniste sobre o jogo, que trata do assunto de maneira bastante ampla, essa temática interessa e instiga especialmente quem reflete sobre ensino e educação. O discurso pedagógico costuma valorizar muito atividades lúdicas e jogos como ferramentas que auxiliam o aprendizado. Mais recentemente, também é comum encontrar termos como gamificação relacionados a diversas áreas da atividade humana e, principalmente, ao ensino. É possivel tratar dessa temática a partir de diversos pontos de vista, dentro de variados quadros teóricos. Aqui, tentamos lançar mão de um olhar a partir do ponto de vista da linguística da enunciação e das observações feitas por Benveniste em seu texto sobre o jogo enquanto uma estrutura que se manifesta das mais variadas formas.

Propomos, então, uma análise linguística do uso de jogos na aula de língua estrangeira. Escolhemos analisar aulas de língua adicional a partir da percep- 
ção de que os jogos são recursos muito utilizados nesse contexto e porque, a partir da leitura de Benveniste, compreendemos que tudo aquilo que denominamos "jogo" comporta características em comum, observáveis em uma variedade imensa de situações (trataremos mais especificamente dessa questão no próximo tópico). A questão que nos instiga é compreender, a partir desse ponto de vista, o que há de específico quando um jogo é proposto na aula de língua adicional e qual pode ser seu valor nessa situação, em que o falante se vê constantemente diante do desafio de criar significação. Partilhamos da visão de Farias (2014, p. 19):

Dessa maneira, entendemos que há um lugar para o estudo enunciativo da língua adicional, cuja abordagem pode trazer contribuições para entender a dimensão da experiência humana na língua quando o falante se propõe a se refazer, por meio da língua, em outra cultura e em outra sociedade.

Este artigo está organizado em duas partes: na primeira, apresentamos a noção de jogo proposta por Benveniste e propomos que as variadas manifestações do jogo podem ser compreendidas como formas complexas do discurso. $\mathrm{Na}$ segunda parte, apresentamos dados coletados de aulas de língua francesa nas quais foram aplicados jogos e propomos uma análise enunciativa das gravações, a partir da dupla descrição da forma linguística e da condição figurativa, considerando que na aula observada há um entrecruzamento de papéis discursivos com a sobreposição de uma relação específica a cada momento.

\section{A NOÇÃo DE JOGO E A LINGUÍSTICA DA ENUNCIAÇÃo}

Gilles Brougère, na obra de 1995 intitulada Jeu et éducation, também destaca que o termo jogo é uma noção aberta, polissêmica e profundamente ambígua; e que refletir sobre o jogo é refletir sobre a linguagem: quais são as representações associadas à palavra "jogo"? Em sua obra, por exemplo, o autor observa que existem diversos niveis de significação relacionados a esse termo, e identifica pelo menos três: há o jogo como atividade lúdica, que pode ser reconhecido objetivamente por observação externa ou do sentimento pessoal; há o jogo como estrutura, como um sistema de regras que existe de formas abstratas, independentemente dos jogadores; e há o jogo como material.

Brougère (1995) foca parte de suas investigações nos sentidos assumidos pela palavra jeu, com base em uma visão sobre a linguagem inspirada em Wittgenstein. Partindo da ideia de que jogo é um termo abstrato, polissêmico e frequentemente ambíguo, propõe reflexões sobre os sentidos assumidos pelo termo: assim, refletir sobre o jogo é também refletir sobre a linguagem. O jogo é um fato de linguagem: nossa compreensão desse termo provém do uso cotidiano, e não do saber científico. De fato, a maioria dos saberes científicos que utilizam essa noção não constrói uma concepção própria de jogo, valendo-se da definição usual - todos consideram seu significado evidente e ninguém o define. No discurso pedagógico e no senso comum, frequentemente se encontram relações entre jogo e educação, diz-se que "se aprende brincando", por exemplo, dando a entender que há algum tipo de relação natural entre o jogo e o ensino. Brougère 
questiona esses discursos, destacando que o jogo passou a ser encarado como educativo a partir do século XIX, com a invenção da infância. No entanto, apenas situar historicamente o surgimento de um discurso ou de uma relação entre atividades não é suficiente para compreender essas relações: é necessário pensar quais jogos, hoje, são utilizados no ensino, de que forma se colocam em sala de aula, com quais objetivos o professor seleciona essas atividades, como decorrem e quais suas consequências.

Benveniste, no artigo "Le jeu comme structure", analisa o jogo como estrutura, a partir da identificação de características próprias do jogo e do estudo dos sentidos assumidos pela palavra jeu em francês. Pinault (2019, p. 77, tradução nossa), ao abordar os estudos do indo-europeu de Benveniste, faz um comentário que também pode se aplicar a este estudo:

A questão não é: o que é um rei indo-europeu? A questão é antes: já que há nos textos uma ou mais palavras que significam "rei", ou que são traduzidas dessa forma, qual é o sentido dessa palavra? Dai uma pergunta mais radical: o que significa "reinar", "governar", em tal ou tal língua, e por extensão em indo-europeu? ${ }^{2}$.

No presente artigo há também esse tipo de investigação: uma vez que jeu refere-se a situações extremamente variadas, o que significa "jogo"? De fato, Benveniste (2015, p. 177, tradução nossa) inicia seu artigo declarando que "imenso é o domínio do jogo"3 e propõe que se trata de uma certa modalidade de toda atividade humana ${ }^{4}$. No entanto, o que Benveniste deseja analisar é o jogo em si e não os jogadores. Sua primeira definição de jogo é: "toda atividade regrada que tem seu fim nela mesma e não visa a uma modificação útil do real" (BENVENISTE, 2015, p. 177, tradução nossa). Benveniste identifica três características principais que definem o jogo: desconsidera as condições do "real", não "serve" a nada (seu fim é a própria realização da atividade) e constitui uma totalidade fechada, desenvolvendo-se dentro de limites próprios.

O jogo, então, caracteriza-se pela forma, mas isso não significa que seja vazio ou destituído de sentidos:

Qualificá-lo [o jogo] como "forma" é opô-lo a um "conteúdo" que seria a realidade mesmo. Mas daí não se segue que o jogo seja forma vazia, produção de atos desprovidos de sentido. A coerência de sua estrutura e sua finalidade interna implicam, ao contrário, um sentido que é como inerente à sua forma e sempre estranho a qualquer objetivo prático [...] (BENVENISTE, 2015, p. 178, tradução nossa) ${ }^{6}$.

2 No original: "La question n'est pas; qu'est-ce qu'un roi indo-européen? La question est plutôt: puisqu'il y a dans les textes un ou des mots qui signifient 'roi', ou qui sont traduits de cette façon, quel est le sens de ce mot? D'où une question plus radicale : que signifie 'régner', 'gouverner', dans telle ou telle langue, et par extension en indo-européen?".

3 No original: "Immense est le domaine du jeu".

4 "Des manifestations infiniment diverses qui y ressortissent et qui font apparaître le jeu moins comme une activité particulière que comme une certaine modalité de tout activité humaine, on a surtout cherché l'origine dans une tendance bio-psychologique qui y trouverait exercice et satisfaction".

5 No original: "toute activité réglée qui a sa fin en elle-même et ne vise pas à une modification utile du réel".

6 No original: "Le qualifier de 'forme', c'est l'opposer à un 'contenu', qui serait la realité même. Mais il ne s'ensuit pas que le jeu soit forme vide, production d'actes dénués de sens. La cohérence de sa structure et de sa finalité interne impliquent au contraire un sens qui est comme inhérente à sa forme et toujours étranger à toute visée pratique [...]". 
Há uma série de regras que mantém o jogo fora do "real" e que não podem ser quebradas, e o sentido é produto dessas condições arbitrárias que limitam e constituem o jogo. A condição dos jogadores também é arbitrária, pois estes assumem um papel determinado pelo jogo em si: "É então o jogo que determina os jogadores, não o inverso. [...] Tudo é condicionado pelo desenrolar do jogo, no interior das condições nas quais ele consiste"7 (BENVENISTE, 2015, p. 178, tradução nossa). O papel que os jogadores vão exercer, portanto, depende das regras e das condições de cada jogo.

Se uma regra não é seguida, o jogo acaba ou não funciona da forma como era esperado, pois "cai no real": "Se uma única regra que o mantém fora do 'real' é violada, o jogo cessa e caímos na realidade"8 (BENVENISTE, 2015, p. 178, tradução nossa). É fácil saber do que Benveniste fala, pois qualquer um que já tenha jogado um jogo de tabuleiro ou de cartas, por exemplo, sabe que o "bom funcionamento" da atividade depende do comprometimento dos jogadores em cumprir os papéis definidos pelo jogo e em seguir suas regras, concordando tacitamente com a invenção momentânea de um instante, de um lugar que parece estar separado do tempo real, da vida real - e talvez venha daí um dos motivos pelos quais os jogos são atividades prazerosas: possuem a capacidade de praticamente inventar um tempo separado do tempo da "vida real" .

Dando continuidade à ideia de que o jogo possui uma realidade própria, Benveniste (2015, p. 179, grifo nosso, tradução nossa) afirma que "há, de fato, uma realidade do jogo, igualmente específica, que tem suas leis, sua necessidade, sua lógica, seu código e até sua linguagem"10. Uma vez que o mito é um elemento essencial do jogo (jocus) e a abstração necessária para a realização dessas atividades só é possivel pela linguagem e na linguagem, ou seja, pelo discurso, o jogo pode ser considerado um objeto de análise linguística, pois envolve a enunciação em diferentes planos. A definição de jocus é linguística, uma vez que é o mito que constitui essa modalidade de jogo. É a linguagem, através do discurso dos sujeitos que dela se apropriam para se enunciar, que se constitui o mito.

Outra observação de Benveniste (2015, p. 178) essencial para a análise do jogo em sala de aula é a ideia de que o jogo cria o sentimento de comunidade: "a ligação do jogo pode ser mais forte do que um parentesco de sangue; ele cria o sentimento muito vivo de uma comunidade que tira dele sua missão, sua honra, seus simbolos". Chamamos a atenção para a noção de comunidade, que pode ser compreendida em um sentido antropológico, mas também em um sentido linguístico ${ }^{11}$. Muitos dos conceitos que à primeira vista parecem pertencer ao

7 No original: "C'est donc le jeu qui détermine les joueur, non l'inverse. [...] Tout est conditionné par le déroulement du jeu, à l'intérieur des conditions en lesquelles il consiste".

8 No original: "Si une seule des règles qui le maintiennent hors du "réel » est violée, le jeu cesse et l'on retombe dans la realité".

9 A relação entre tempo e jogo é mais detidamente explorada por Giorgio Agamben (2005) em um ensaio no qual fala do país dos brinquedos, um lugar fictício que faz parte da história de Pinóquio, de Collodi. Em determinado momento, o personagem chega a esse lugar, no qual habitam apenas crianças de 8 a 14 anos - e só existe jogo. Nessa configuração em que a vida é invadida pelo jogo, o tempo se acelera e altera o calendário: este é paralisado e destruído, transformando-se em um contínuo de um eterno dia de "pandemônios", "algazarras" e "badernas". Essa ficção em que existe apenas jogo e o tempo é alterado nos ajuda a pensar na relação com a temporalidade que se estabelece de maneira diferente quando jogamos. Essa observação é crucial para pensar o uso de jogos como recursos didáticos, já que numa sala de aula, em geral, a proposta dos jogos parte do professor, e cabe a ele mediar a realização da atividade para garantir que o jogo cumpra seu papel. Parte importante dessa função é intervir para que os alunos se engajem dessa forma, sem permitir que o jogo "caia no real" (ou num "pandemônio"). Para uma discussão mais aprofundada do texto de Agamben (2005) em sua relação com o pensamento de Benveniste, consulte-se Silva (2019).

10 No original: "Il y a bien en effet une réalité du jeu, tout aussi spécifique qui a ses lois, sa nécessité, sa logique, son code et jusqu'à son langage".

11 Oliveira e Silva (2018) lançam um olhar para as noções de comunidade, pertença social e sociedade a partir do ponto de vista da linguística enunciativa de Émile Benveniste, propondo um estudo das relações interlocutivas em sala de aula para avaliar, a partir dessas noções, como a proposta didática favorece a inclusão ou a exclusão dos alunos na comunidade linguística. 
domínio das Ciências Sociais e não à Linguística podem ser explorados por esse viés: afinal, é do homem na língua que falamos aqui.

\section{O jogo como forma complexa do discurso}

A partir do texto de Benveniste, entendemos que o jogo é uma estrutura que pode se manifestar nas mais diversas situações, com características específicas em cada situação concreta. Para propor uma análise enunciativa da aplicação de jogos em sala de aula, entendemos de início que as manifestações do jogo podem ser compreendidas como formas complexas do discurso.

No final do texto "O aparelho formal da enunciação", Benveniste (1989a, p. 90, grifo nosso) deixou aos seus futuros leitores uma frase enigmática cujos sentidos continuam a ser explorados até hoje: "Amplas perspectivas se abrem para a análise das formas complexas do discurso". O termo "formas complexas do discurso" não é utilizado em nenhum outro texto de sua autoria, mas pode ser lido em conjunto à sua obra para possibilitar uma interpretação do que seriam essas formas. Há ainda um breve comentário sobre a maneira como seria possivel analisá-las: "Essas situações [referindo-se ao hain-teny e ao monólogo] exigiriam uma dupla descrição, da forma linguística e da condição figurativa" (BENVENISTE, 1989a, p. 88).

Flores e Endruweit (2013) indicam que, para compreendê-las, é necessário recorrer a outros textos, como "Semiologia da Língua" (BENVENISTE, 1989b), no qual são propostas duas formas de análise: intralinguística e translinguística, como caminhos para ultrapassar a noção saussuriana do signo como único princípio. Enquanto a intralinguística seria responsável "pela abertura de uma nova dimensão de significância, a do discurso, que denominamos semântica, de hoje em diante distinta da que está ligada ao signo, e que será semiótica", a via translinguística de textos se daria "pela elaboração de uma metassemântica que se construirá sobre a semântica da enunciação" (BENVENISTE, 1989b, p. 67). A leitura de Flores e Endruweit (2013) é de que formas complexas do discurso, translinguística, metassemântica e semiologia de segunda geração são termos relacionados, que apontam para possibilidades de análises enunciativas para além das marcas da enunciação no enunciado: estaria aí a perspectiva de analisar as formas complexas.

Diversos autores têm se debruçado para propor análises sobre essas noções. Entre eles, Bressan (2010) estuda a metassemântica, um tipo de análise translinguística. Na elaboração de uma metassemântica, define seis principios, entre eles, o princípio de que a metassemântica analisa as formas complexas do discurso. Essa leitura parte da diferenciação que Benveniste faz entre o semiótico e o semântico, dois modos distintos de significância que estão combinados na língua, cada um tendo dois modos de ser na língua: no sentido e na forma. Segundo Benveniste (1989b, p. 224), a unidade de análise da metassemântica seria justamente os dois modos de ser da lingua, no sentido e na forma. A autora aponta que não é possivel ter certeza, a partir de Benveniste, do que a metassemântica deve comportar: textos, obras ou além disso? Sua leitura, no entanto, aponta como unidade de análise da metassemântica precisamente as formas complexas do discurso. E quais seriam essas formas? 
Entendemos, então, que qualquer fato humano, como jogo de futebol, baile, festa, cerimônia de casamento, jantar, entrega do Oscar, Festival de cinema, consulta médica, aula, diálogo, a arte em suas variedades (teatro, filme, televisão, ópera, música, imagens, reproduções plásticas), obras em prosa, em verso, ou científicas, em que seja possível construir a relação entre o método global de apreensão do sentido e o método analítico, tendo por base a semântica da enunciação, pode ser objeto de análise da translinguística (BRESSAN, 2010, p. 110).

Seguindo a leitura de Bressan (2010), podemos propor que os jogos, em sua imensa variedade, sejam considerados formas complexas do discurso, e objetos de análise metassemântica, considerando as particularidades de cada uma das inúmeras formas pelas quais o jogo se apresenta. Ela mesma propõe como exemplo uma análise metassemântica de uma partida de futebol, considerando os vários planos de enunciação envolvidos (nesse caso, não é apenas o jogo futebol que é analisado, mas o futebol como fenômeno social, que envolve uma série de elementos que não está implicada nas regras do jogo em si).

Detendo-nos no jogo utilizado como recurso didático, defendemos que seja considerado uma forma complexa do discurso a partir da percepção de que, na cena enunciativa da sala de aula, podemos compreender as complexas relações entre forma e sentido envolvidas no processo de apropriação da língua adicional pelos sujeitos aí implicados a partir de uma dupla descrição, da forma linguística e da condição figurativa, conforme nos ensina Benveniste no final do texto "O aparelho formal da enunciação".

Para analisar a relação entre condição figurativa e forma linguística, é necessário considerar o quadro figurativo da enunciação, do qual fala Benveniste (1989b). É a acentuação discursiva com o interlocutor que caracteriza a enunciação, "seja este real ou imaginado, individual ou coletivo" (BENVENISTE, 1989 b, p. 87). Silva (2013), a partir dessas categorias, analisa as intervenções do professor no texto do aluno no contexto do ensino de produção textual no ensino superior. De início, pensando no contexto do jogo, propomos alguns exemplos de como se dariam essas formas de relação intersubjetiva com base na leitura que Silva faz de Benveniste, a partir da consideração de possiveis intervenções do professor:

Guadro 1 - Formas do discurso (SILVA, 2013) e o uso do jogo na aula

\begin{tabular}{|l|l|}
\hline Formas reais & $\begin{array}{l}\text { O professor "interrompe” o jogo para corrigir uma forma } \\
\text { gramatical incorreta, por exemplo. }\end{array}$ \\
\hline $\begin{array}{l}\text { Formas } \\
\text { imaginadas }\end{array}$ & $\begin{array}{l}\text { Expectativas que o professor tem em relação ao aluno e que o } \\
\text { aluno tem em relação ao professor. }\end{array}$ \\
\hline $\begin{array}{l}\text { Formas } \\
\text { individuais }\end{array}$ & $\begin{array}{l}\text { O professor faz intervenções individuais no decorrer do jogo, } \\
\text { auxiliando ou incentivando, por exemplo. }\end{array}$ \\
\hline Formas coletivas & $\begin{array}{l}\text { O professor se dirige à turma - por exemplo, quando explica as } \\
\text { regras do jogo, que se destinam a todos os participantes. }\end{array}$ \\
\hline
\end{tabular}

Fonte: Elaborado pelas autoras. 
O Quadro 1 é apenas um exemplo de como se estabeleceriam as relações intersubjetivas em sala de aula durante um jogo; no entanto, como veremos mais detidamente nas análises, o jogo em sala de aula apresenta especificidades, pois está inserido em um contexto de ensino-aprendizagem que altera sua configuração. Por exemplo: embora o jogo como estrutura não sirva a nada, o professor tem objetivos específicos quando propõe um jogo para os alunos; além disso, há uma figura de autoridade (o professor) que pode se incluir como jogador ou colocar-se como um observador ou orientador. Nesse sentido, acreditamos que a observação de jogos em sala de aula é interessante justamente por conta da observação do entrecruzamento dos papéis discursivos assumidos pelos locutores.

No caso da aula que analisamos, cujo contexto será mais detalhado na próxima seção, identificamos diversos papéis discursivos que os locutores assumem, que se intercruzam durante a interação. Em certos momentos, um ou outro papel se sobressai: há o papel de jogador, os papéis de professor e aluno e mesmo o papel familiar mãe-filhos, visto que alguns alunos faziam parte de uma família. Tentamos, na análise, fazer uma descrição da relação entre forma linguística e condição figurativa, levando em conta as especificidades do jogo.

\section{Procedimentos e metodologia de ANÁlise}

A fim de propor uma análise de caráter enunciativo, gravamos três aulas de língua francesa como língua adicional nas quais foram aplicados jogos variados. As gravações foram realizadas no primeiro trimestre de 2019 em um centro de línguas na cidade de Porto Alegre, vinculado a uma escola estadual, mas que funciona de maneira independente, acolhendo alunos externos à comunidade acadêmica. As três aulas foram ministradas pela mesma professora, porém em turmas distintas. Ao fazer o contato com a escola, explicamos apenas que buscávamos estudar a aplicação de jogos em aulas de língua estrangeira e que entendiamos jogo de maneira ampla, compreendendo, por exemplo, atividades em que os alunos são convidados a assumir determinados papéis (por exemplo: cliente e garçom em um restaurante).

A professora nos convidou a assistir a três aulas: na primeira, os alunos jogaram bingo a fim de revisar os números em francês para a prova da semana seguinte; na segunda, jogaram um jeu de sept familles ${ }^{12}$. Na terceira aula, foram aplicados dois jogos de trilha: o primeiro trazia perguntas e ordens, como "conjugue o verbo avoir", "conte de 1 a 10", "diga seu nome", "toque na orelha do vizinho"; os jogadores deveriam cumprir as ordens de cada casa para poder avançar. O segundo jogo era semelhante, mas cada casa trazia uma palavra que deveria estar contida em uma pergunta formulada pelo aluno ao parar nessa casa. Neste trabalho, escolhemos analisar mais detidamente o primeiro jogo da terceira aula.

$\mathrm{Na}$ aula de língua adicional, o objetivo mais geral é que os sujeitos se insiram na "outra" língua, processo esse que passa necessariamente por outra cultura. Essa inserção ocorre, em sala de aula, por meio das relações intersubjetivas que se estabelecem de diversas formas: professor-aluno (forma individual), professor12 Trata-se de um jogo de cartas em que há "famílias" de elementos, agrupadas conforme uma determinada temática (na aula
observada, o tema era a mitologia grega). As cartas são misturadas e distribuídas entre os jogadores e o objetivo é reunir as cartas conforme suas famílias. 
-alunos (forma coletiva), aluno-aluno, entre outras. Ao propor um jogo, o professor também propõe que os alunos assumam papéis discursivos além dos de "aluno", e pode mesmo se incluir na cena do jogo, assumindo mais o papel de jogador do que de professor. No entanto, o jogo permanece submetido ao contexto de sala de aula, apresentando especificidades. Nos recortes selecionados, observamos a intervenção do professor em algum momento do fio do discurso do jogo.

Destacamos que a transcrição, procedimento essencial em nossa análise, é uma modalidade da enunciação (FLORES, 2006) em si: ao transcrever, o analista realiza dois atos: uma operação de ciframento e outra de deciframento: em um primeiro momento, a partir dos dados gerados e das convenções escolhidas, o analista busca mostrar o fato, criando um modelo da realidade. Em um segundo momento, lê as transcrições, decifrando o que mostrou. No entanto, uma vez que há sempre um resto que escapa a qualquer formalização, a transcrição é também um dizer. A transcrição, portanto, é um ato enunciativo composto por um mostrar e um dizer. A enunciação é sempre um ato único, efêmero, e o mesmo ocorre com a transcrição: na medida em que é singular e jamais será integral, nunca será capaz de retratar objetiva e integralmente o que busca representar, já que algo sempre escapa ao sujeito que enuncia. Ainda, retomando a pesquisa de Bressan (2010, p. 126), destacamos que a análise das formas complexas do discurso é sempre uma interpretação parcial do analista: entre as razões para a parcialidade, está a condição espaço-temporal do analista, que difere daquela do objeto de análise; o fato de que o analista nem sempre encontra as marcas deixadas pelo sujeito analisado e a subjetividade que existe tanto no analista quanto no objeto de análise.

Para tentar ilustrar como enxergamos a análise translinguística e o entrecruzamento dos papéis discursivos assumidos pelos locutores, utilizaremos o triângulo de Kanizsa ${ }^{13}$ :

Figura 1 - Triângulo de Kanizsa

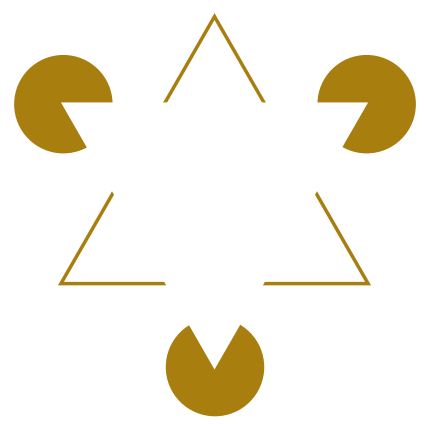

Podemos pensar que o triângulo marrom representa a materialidade linguística sobre a qual incide a análise; os círculos marrons, os três diferentes níveis que identificamos e consideramos para a análise, nos quais varia a condição figu-

13 Localizamos essa imagem a partir da busca do termo Gestalt no buscador de imagens do Google. Conforme Normand (2009, p. 150), "Benveniste introduz uma filosofia do sujeito e do sentido, uma fenomenologia que daria à linguagem um lugar central, constitutivo do ser humano", o que nos leva a estabelecer uma ponte entre a sua teoria da linguagem e teorias psicológicas da percepção, notadamente a Fenomenologia de Merleau-Ponty e a de Gestalt. Evidentemente, estabelecer essa relação de forma mais profunda demanda novos estudos. 
rativa: o jogo, a situação pedagógica e a família. Esses três niveis de relações determinam os papéis discursivos que os sujeitos ocupam nas análises. O triângulo branco representa a análise, sempre parcial e apoiando-se não apenas na materialidade linguística, mas também em elementos que parecem externos à língua, mas que determinam a forma como os locutores assumem a posição de sujeito.

Com essa representação, procuramos mostrar que é necessário levar em consideração a situação específica de enunciação. No caso deste trabalho, não estamos analisando apenas um jogo, mas um jogo que está submetido ao âmbito pedagógico, pois ocorre em uma sala de aula e sua aplicação tem determinados objetivos. Além disso, a questão da relação familiar que existe entre os alunos também tem de ser levada em conta, pois em determinados momentos da análise esse nivel sobrepõe-se aos outros. Nos trechos a seguir, observamos que o nivel pedagógico das relações, na maior parte do tempo, sobrepôs-se ao nível do jogo e ao nivel das relações familiares.

\section{Análise enunciativa da aplicação de jogos em aulas de língua francesa}

Nesta seção, apresentaremos alguns recortes de duas cenas enunciativas de uma aula de francês, a partir das transcrições de gravações. Os alunos dessa turma são uma família; na gravação, estavam presentes uma adulta e seus dois filhos, de 10 e 12 anos. Todos estudam francês há cerca de um ano, situando-se em um nivel iniciante. Cada recorte será nomeado com uma frase-síntese, que funciona como quadro geral de interpretação do ato de linguagem mais evidente na cena enunciativa, do ponto de vista da análise, semelhante à maneira como procede Costa Silva (2009) em estudo sobre a aquisição da linguagem. Optamos por transcrever os recortes de acordo com a ortografia do francês e do português, fazendo transcrições fonológicas quando necessário. Utilizamos dois sinais gráficos importantes:

- (...) para marcar um trecho que não foi transcrito

- [ ] quando há um comentário da analista sobre a cena

\section{RECORTE ENUNCIATIVO 1: estou orgulhosa!}

[ALUNA 1 joga os dados e para em um espaço do tabuleiro]

PROFESSORA: Qu'est que c'est?

ALUNA 1: moi nationalité [interrompida]

PROFESSORA: dis ta nationalité

ALUNA 1: moi nationalité... moi nationalité est /brasili'an/? [repete algumas vezes]

PROFESSORA: brésilienne

ALUNA 1: brésilienne

PROFESSORA: oui, nacionalidade brasileira

ALUNA 2: mas a frase toda tá correta?

PROFESSORA: oui, c'est ma. "Moi" sou "eu", "ma" é "minha". Ma nationalité. Mas tá muito bom! Ou alors tu peux dire "eu sou brasileira"

ALUNA 2: je suis brésilienne

PROFESSORA: voilà! As duas formas

ALUNA 1: eu queria enfeitar mais [ri]

PROFESSORA: mas tá ótimo! [inaudivel] je suis fière de toi! Estou orgulhosa! 
Nessa aula, os alunos participavam de um jogo no qual deveriam seguir as instruções de cada espaço do tabuleiro ao parar com sua peça sobre ele. A aluna 1 (uma criança de cerca de dez anos) parou em um espaço que exigia que ela falasse sua nacionalidade. Ao cumprir a instrução, ela utiliza o pronome tônico moi em vez do possessivo ma, mas a professora opta, num primeiro momento, por não corrigir essa construção, chamando atenção apenas para a pronúncia de brésilienne. No entanto, uma segunda aluna (adulta, mãe da aluna 1) percebeu que havia algo de diferente na construção da frase da aluna 1 , e, nesse momento, interveio para questionar a professora. A professora, então, explica o uso de ma, dirigindo-se às duas, mas em seguida acrescenta que a construção da aluna 1 estava muito boa. A aluna 1 parece se justificar, dizendo que queria "enfeitar" a frase ao incluir moi, e a professora a elogia novamente. Percebemos, que, aqui, a relação familiar atravessa a cena do jogo, quando a mãe da aluna 1 questiona a professora sobre a construção da frase, algo que dificilmente ocorreria no nivel da relação entre colegas. Além disso, percebe-se que a professora possivelmente optou por corrigir apenas a forma que parecia mais relevante (aquela que era o objeto da ordem do tabuleiro) naquele momento, sendo convocada a corrigir a outra forma por uma segunda aluna, que estava observando a interação.

Ao dizer "eu queria enfeitar mais", interpretamos que a aluna estava tentando mobilizar a língua adicional à sua própria maneira. Na busca por significar em francês, procurou recursos que pudessem, talvez, compor uma frase mais complexa sintaticamente. Ao dizer "mas tá muito bom!", "mas tá ótimo" e "je sui fière de toi! Estou orgulhosa!", interpretamos na fala da professora a tentativa da aluna de mobilizar outros recursos, de "enfeitar". Entendemos a partir da sua fala algo como: "a frase não está correta em francês, mas estou orgulhosa da sua tentativa de mobilizar outros recursos linguísticos para dizer o que queria dizer".

Também chamamos a atenção, aqui, para a posição da professora, que não se coloca como jogadora, mas sim como alguém externa ao jogo, que orienta sobre seu prosseguimento e interfere para auxiliar e corrigir.

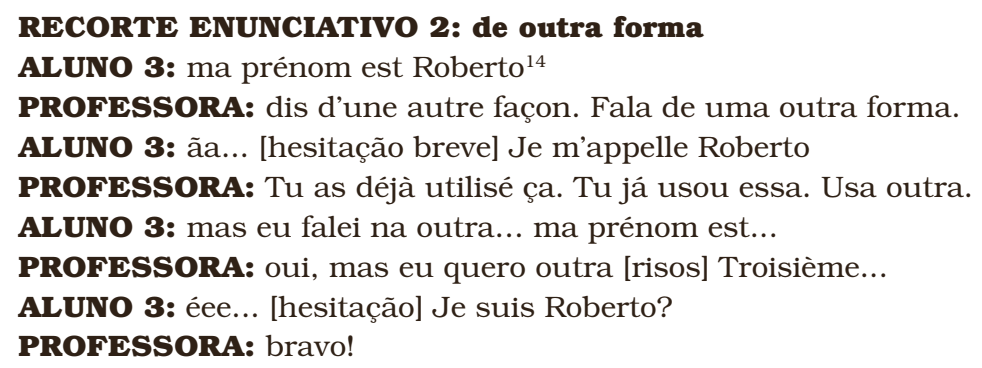

Nesse trecho, o aluno parou em um espaço do tabuleiro pelo qual já tinha passado outras vezes durante o jogo. A instrução era dizer o seu nome, e ele prontamente respondeu "ma prénom est Roberto". Esse enunciado traz uma incorreção, pois, em francês, prénom é uma palavra masculina, e, portanto, de- 
ve ser precedida pelo possessivo mon, e não ma. No entanto, a professora não chamou a atenção para esse detalhe. Ela poderia ter aceitado a resposta, assumindo que o enunciado do aluno estava adequado para a situação apesar da incorreção; ou poderia ter corrigido o uso do possessivo. No entanto, ela interveio em outro sentido: ao perceber que o aluno estava repetindo uma sentença que já tinha dito anteriormente, pediu que ele falasse de outra forma. O aluno, então, após uma breve hesitação, usa a construção “je m’appelle" em vez de "ma prénom est...”. A professora, mais uma vez, intervém, dizendo que ele já tinha utilizado também aquela construção e pedindo que pensasse em uma terceira construção.

Nesse ponto, o aluno diz que já tinha enunciado outra construção, mas a professora insiste no pedido por uma terceira forma. Ele, enfim, profere uma sentença construída com "je suis...", e a professora o elogia ("bravo!"). Nesse trecho, percebemos que a relação professor-aluno sobrepõe a situação do jogo, pois a professora "muda as regras", pedindo ao aluno que formule a frase de outra maneira. Enquanto jogador, o aluno cumpriu as regras; mas como aluno sua manifestação não foi aceita. Interpretamos que a partir do ponto de vista da professora o aluno não estava cumprindo os objetivos que ela imaginava para o jogo e para a aula de língua ao enunciar frases já ditas anteriormente, ainda que a forma linguística das frases pudesse estar adequada. Suas intervenções exigiram, por meio de uma espécie de negociação, que ele elaborasse novos enunciados a partir dos recursos linguísticos que tinha para tal tarefa.

Esse recorte opõe-se ao anterior, no qual a professora elogiou a aluna 1 por tentar mobilizar recursos linguísticos diferentes ao enunciar na língua adicional. Percebemos que em seu fazer a professora valoriza essas tentativas de criar significação por meio de "outras formas".

\section{CONSIDERAÇÕES FINAIS}

A partir da análise dos recortes enunciativos, percebemos que, nas situações apresentadas, a configuração de sala de aula e os papéis discursivos professor-alunos prevalecem sobre o jogo. A professora coloca-se como externa ao jogo, orientando sobre o seu funcionamento e permanecendo a todo momento no papel de corrigir e incentivar. Percebemos que, no primeiro recorte, a professora valoriza a iniciativa da aluna de tentar "enfeitar" a frase mobilizando recursos linguísticos diversos, ainda que a forma linguística não estivesse adequada. No segundo recorte, ocorreu o inverso: a forma enunciada pelo aluno foi perfeitamente adequada, mas a professora exigiu que este fizesse o esforço de mobilizar outros recursos para dizer o que era exigido, mudando as regras do jogo.

A metodologia elaborada para a observação do funcionamento das formas complexas do discurso nos revela, então, que o "jogo" pode ter suas regras quebradas, questionadas ou suspensas em função de ora mobilizar condição figurativa anterior ou externa ao jogo (primeiro recorte), ora em função de reforçar condição figurativa interna ao jogo, porém não pertencente explicitamente às regras do presente jogo (segundo recorte). Tais resultados retratam não tanto as limitações do uso de jogos em aulas de língua adicional, mas a inclusão de novos "dados" ou "regras" que aparecem durante a execução do jogo, lembrando sempre que se trata de um jogo com a linguagem, instituição em que o tempo e condições figurativas são características fundamentais. 
Com este artigo, esperamos ter apresentado alguns pontos relevantes para pensar a aplicação de jogos em sala de aula e as especificidades inerentes a esse contexto. Acreditamos que novas pesquisas devam ser realizadas, com o ensino de jogos em outras línguas, tanto para corroborar as constatações ora apresentadas quanto para subsidiar a produção de diretrizes de ensino de jogos em aulas de linguas, a partir de um ponto de vista enunciativo, meta de longo prazo.

\section{The game as a COMplex form of SPEech: AN ENUNCIATIVE APPROACH OF A French CLASS}

Abstract: This paper proposes an enunciative analysis from the perspective of enunciation linguistics from Émile Benveniste of a French as second language class in which the game was used as a didactic resource. In the first part, we propose that the game can be understood as a complex form of discourse. In the second part, we analyze transcribed excerpts from this class. We propose that, in this context, the game assumes a specific configuration because the game is submitted to a situation of teaching-learning in which the speakers assume discursive roles that intertwine.

Keywords: Enunciation. Complex forms of speech. Game. French language teaching. Émile Benveniste.

\section{REFERÊNCIAS}

AGAMBEN, G. Infância e história: destruição da experiência e origem da história. Tradução Henrique Burigo. Belo Horizonte: Editora da UFMG, 2005.

BENVENISTE, E. O aparelho formal da enunciação. In: BENVENISTE, E. Problemas de Linguística Geral II. Campinas: Pontes, 1989a. p. 81-90.

BENVENISTE, E. Semiologia da lingua. In: BENVENISTE, E. Problemas de Linguistica Geral II. Campinas: Pontes, 1989b. p. 43-67.

BENVENISTE, E. Le jeu comme structure. In: LAPLANTINE, C.; PINAULT, G. J. (org.). Langues, cultures, religions. Paris: Lambert-Lucas, 2015. p. 177-183.

BRESSAN, N. T. W. O deserto da metassemântica esconde tamareiras em flor: o legado translinguístico de Émile Benveniste. 2010. 137 f. Tese (Doutorado em Estudos da Linguagem) - Universidade Federal do Rio Grande do Sul, Porto Alegre, 2010.

BROUGÈRE, G. Jeu et éducation. Paris: L'Harmattan, 1995.

COSTA SILVA, C. L. da. A criança na linguagem: enunciação e aquisição. Campinas: Pontes, 2009.

FARIAS, B. S. Do testemunho de uma experiência na linguagem para uma reflexão enunciativa sobre o fazer linguístico implicado em aprender e ensinar português como língua adicional. 2014. 174 f. Dissertação (Mestrado em Teorias do Texto e do Discurso) - Universidade Federal do Rio Grande do Sul, Porto Alegre, 2014.

FLORES, V. N. Entre o dizer e o mostrar: a transcrição como modalidade de enunciação. Organon, Porto Alegre, n. 40/41, p. 61-75, jan./dez. 2006. 
FLORES, V. N. Introdução à teoria enunciativa de Benveniste. São Paulo: Parábola Editorial, 2013.

FLORES, V. N.; ENDRUWEIT, M. L. A noção de discurso na teoria enunciativa de Émile Benveniste. Revista MOARA - Revista Eletrônica do Programa de Pós-graduação em Letras, v. 1, n. 38, p. 196-208, ago. 2013.

LAPLANTINE, C.; PINAULT, G. Introduction. In: LAPLANTINE, C.; PINAULT, G. (org.). Langues, cultures, religions. Limoges: Lombert-Lucas, 2015. p. 177-183. NORMAND, C. Interior/exterior: função de uma metáfora. In: NORMAND, C. Convite à Linguística. São Paulo: Contexto, 2009. p. 135-152.

OLIVEIRA, A. M.; SILVA, S. A pertença do aluno à comunidade linguística da sala de aula: um estudo enunciativo das relações interlocutivas em uma turma de produção textual. Letra Magna - Revista de Divulgação Científica em Língua Portuguesa, Linguística e Literatura, v. 4, n. 23, 2018. Disponivel em: http:// www.letramagna.com/artigos_23/artigo18_23.pdf. Acesso em: 10 maio 2021.

PINAULT, G. J. Benveniste et les études indo-européenes. In: D’OTTAV, G.; FENOGLIO, I. (dir.) Émile Benveniste, 50 ans après les "Problèmes de linguistique générale”. Paris: Rue D'ulm Eds, 2019.

SILVA, S. O homem na língua: uma visão antropológica da enunciação para o ensino de escrita. 2013. 221 f. Tese (Doutorado em Estudos da Linguagem/ Teorias do Texto e do Discurso) - Universidade Federal do Rio Grande do Sul, Porto Alegre, 2013.

SILVA, S. A especificidade da noção de jogo em Agamben: influência da análise linguística ou hipótese da infância? Controvérsia, São Leopoldo, v. 15, n. 2, p. 97-105, maio/ago. 2019. 